\title{
Coronectomy: An aware technique unaware to oral and maxillofacial surgeons (review)
}

\author{
Dr Anand Kumar ${ }^{1,}$ Dr Ruchika Khanna ${ }^{2}$,Dr Arun K Goyal ${ }^{3}$, Dr Ankit Jain ${ }^{4}$ \\ ${ }^{I}$ (Dept of oral surgery Career post graduate institute of dental sciences Lucknow UP India) \\ ${ }^{2}$ (Dept of oral medicine and radiology Teerthanker mahaveer dental college \& university Moradabad India) \\ ${ }^{3}$ (Dept of oral surgery Teerthanker mahaveer dental college \& university Moradabad UP India)
}

\begin{abstract}
Coronectomy (Intentional Partial Tooth Removal) American Dental Association-D7251 is a new procedure introduce in oral and maxillofacial surgery for the removal of crown of mandibular third molar. Coronectomy is performed when a neurovascular complication is likely if the entire impacted tooth is removed. Very few studies are going with this procedure and all studies are concluding the same that this procedure has no harm with the patient as well economically cheap procedure but still this procedure is not in use as well as no further studies and researches are going with this procedure. Why oral and maxillofacial surgeons are not using this procedure or why no any further studies are going with this procedure?

(Keywords: coronectomy, deliberate vital root retention, partial root removal, partial odontectomy)
\end{abstract}

\section{Introduction}

Coronectomy is a technique that reduces morbidity of the nerve after operation on high-risk mandibular third molars. Coronectomy or intentional partial odontectomy is a procedure whereby the root(s) of a lower third molar tooth that is deemed close to the inferior alveolar canal on radiographic imaging is left in-situ. The technique was first described by Knutsson et al. in 1989 but was not popularised due to the reported complications of root exposure and infection from the technique [1]. Coronectomy is a relatively new procedure and to date there have only been a handful of publications that investigate its' effectiveness as a treatment modality. If the third molar (or indeed any mandibular tooth) requiring extraction is in close proximity to the IAN, then traditionally panoral radiography[Fig-1] has been the mainstay for evaluation. Impacted mandibular third molar teeth are in close proximity to the lingual, inferior alveolar, mylohyoid and buccal nerves[2]. Coronectomy technique involves using the buccal approach and removal of buccal bone using a fissure bur down to the amelo-dentinal junction (crown root junction)[Fig 2]

The third molar is the tooth that is usually involved, but occasionally the second molar and even the first molar roots can be in close relationship to the inferior alveolar nerve. The technique of coronectomy, or deliberate vital root retention, has been proposed as a means of removing the crown of a tooth but leaving the roots, which may be intimately related with the inferior alveolar nerve, untouched so that the possibility of nerve damage is reduced. 


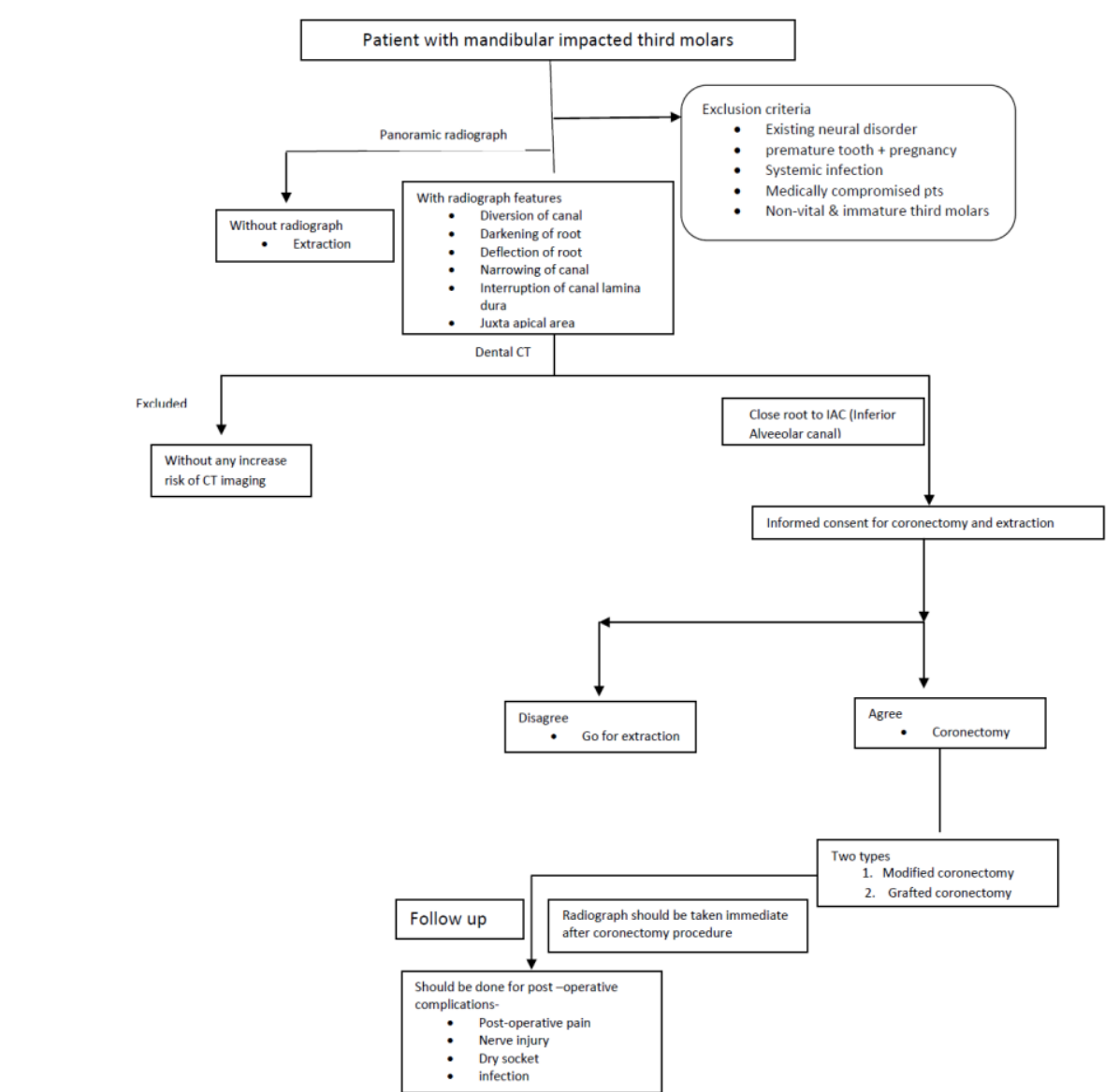

Fig 1: Evaluation and follow un criteria for coronectomv
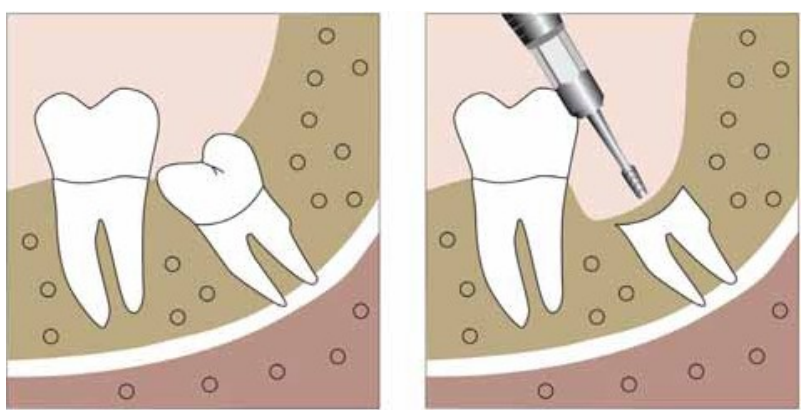

Fig2: Coronectomy technique: resection of the crown 2-3 mm below the enamel of the tooth.

(Chkoura Ahmed et. al. Coronectomy of Third Molar: A Reduced Risk Technique forInferior Alveolar Nerve Damage. Dent Update 2011; 38: 267-276)

The disadvantages of this technique include deep periodontal pockets on the distal of the second molars (similar to those after extractions in comparable circumstances), root migration with the possible need of a second procedure, dry sockets, local postoperative infections, postoperative pain and inadvertent root removal, or root walk-out during surgery which may increase the risk of IANI (also known as a failed coronectomy) $[4$, $5,6,7,8]$

Coronectomy of lower third molars is NOT carried out in the following situations [9]

- Wisdom tooth roots are not touching the IAN canal

- Wisdom tooth with either active root tip or crown infection

- Pre-existing numbness of the IAN

- Pre-existing mobility of the tooth as any retained roots may act as a mobile foreign body and become a nidus for infection / migration.

- Teeth that are horizontally impacted along the course of the IAN as sectioning the tooth crown could endanger the IAN. 
- Systemic condition predisposing to local infection such as diabetes, AIDS and concurrent chemotherapy.

- Local factors predisposing to infection such as metabolic bone diseases (e.g. fibrous dysplasia), history of radiotherapy to the lower jaw.

\section{Modern concept in coronectomy-}

Two types of coronectomy [10] procedure is reported recently are-

1. Modified coronectomy

2. Grafted coronectomy

As with the standard coronectomy, MGC involves the removal of the crown and part of the root/s of an impacted MTM in cases with a high risk of IANI. This modified procedure introduces steps to prevent the complication of intraoperative root loosening. It accomplishes this by stabilizing the radicular fragment during cutting as well as when separating the coronal section off, thus overall decreasing the risk of nerve injury. Yet as another modification, to reduce or prevent periodontal pockets on the distal of the second molar, the technique calls for the creation of periodontal "scaffolding,"which is achieved through grafting, thus the name Modified and Grafted Coronectomy.

\section{Discussion}

Coronectomy was developed to reduce the incidence of iatrogenic injury to the inferior dental nerve, which can be a result of routine mandibular third molar surgery, but it is not widely accepted despite early studies that all showed positive results. . Several articles have reported this technique with less complications and more promising results, yet it was understandable that dentists and oral surgeons would not be convinced until a well-designed study can show its safety in terms of reduced risk of IDN and other surgical complications. Pogrel et al evaluated 41 patients who underwent coronectomy on 50 lower third molars, with follow-up of at least 6 months. This technique was used because there was radiographic evidence of a close relationship between the roots of the tooth and the inferior alveolar nerve. The authors [Table-1] reported that there were no cases of inferior alveolar nerve damage in this study. Preoperative and postoperative prophylactic antibiotics; one paper suggested postoperative antibiotics only; another paper suggested no antibiotics were necessary; and the other two papers did not mention antibiotics Pogrel 2004[13], O’Riordan 2004[14], Renton 2004[15] respectively.

It has now been accepted in USA as a standard and is no longer a controversial treatment option at Third Molar Multidisciplinary Conference in Washington, DC, on October 19, 2010, and AAOMS ParCare 2012[21, 22].

Dr. Mike Y Y LEUNG \& Prof. Lim K CHEUNG[20] conducted a prospective cohort study of 4338 wisdom tooth surgeries between 1998 and 2005 in the Prince Philip Dental Hospital, which is by far the largest study reported in the literature. The prevalence of $\mathrm{LN}$ and IDN injuries were $0.69 \%$ and $0.35 \%$, respectively.

Many studies have reported the frequency of nerve injury during the removal of third molars (Robinson 1997) and most indicate that inferior alveolar nerve function is disturbed after $4-5 \%$ of procedures (range $1.3-$ $7.8 \%)[23]$.

These figures were relatively low when compared to those reported in the literature. $66.7 \%$ of IDN deficit and $72.0 \%$ of LN deficit recovered fully within the follow-up period of 24 months. It was also noticed the recovery of the neurosensory deficit was most significant in the first 6 months after the injury. Bruce RA, Frederickson GC, Small GS in 1980 demonstrated that increasing age is associated with a higher frequency of inferior alveolar nerve injury (14-24 year old patients $1.2 \%$; 35-81 year-old patients $9.7 \%$ ).

Monaco G et al 2012 evaluated the postoperative complications of 43 coronectomies of impacted mandibular third molars in 37 patients (17 men and 20 women) and concluded that Coronectomies are safer to perform than complete extractions in situations in which the third molar is in close proximity to the mandibular canal. Root migration generally is asymptomatic, but in a case in which the patient underwent a second operation, the risk of the patient's experiencing neurological injuries was reduced.. The authors used cone-beam computed tomographic images to determine that all of the teeth that underwent a coronectomy were in close proximity to the IAN [24].

IANI was the most serious complication which occurred during some failed coronectomies, where the remaining root was inadvertently mobilized during surgery. This mandated the surgeons to proceed with the extraction of the entire root in $4-38 \%$ of the cases $[12,14]$.

The clear benefit of a successful coronectomy is the avoidance of IANI. The disadvantages of this technique include deep periodontal pockets on the distal of the second molars (similar to those after extractions in comparable circumstances), root migration with the possible need of a second procedure, dry sockets, local postoperative infections, postoperative pain and inadvertent root removal, or root walk-out during surgery which may increase the risk of IANI (also known as a failed coronectomy) $[4,5,25]$ 
Coronectomy: An aware techgnique unaware to oral and maxillofacial surgeons (review)

\begin{tabular}{|c|c|c|c|c|c|}
\hline Ref & Author & Article & Published in Journal & year & Study Design \\
\hline 1 & $\begin{array}{l}\text { Knutsson et. } \\
\text { al. }\end{array}$ & $\begin{array}{l}\text { Postoperative status after partial } \\
\text { removal of the mandibular third molar. }\end{array}$ & Swed Dent J. & 1989 & $\begin{array}{l}\text { Retrospective } \\
\text { study }\end{array}$ \\
\hline 11 & Freedman & $\begin{array}{l}\text { Intentional partial odontectomy: review } \\
\text { of cases }\end{array}$ & J Oral Maxillofac Surg & 1997 & $\begin{array}{l}\text { Case series over } \\
6 \text { years }\end{array}$ \\
\hline 12 & Pogrel et al & $\begin{array}{l}\text { Coronectomy: a technique to protect } \\
\text { the inferior alveolar nerve" }\end{array}$ & J Oral Maxillofac Surg & 2004 & $\begin{array}{l}\text { Prospective } \\
\text { cohort }\end{array}$ \\
\hline 13 & $\begin{array}{l}\text { O'Riordan B } \\
\text { C }\end{array}$ & $\begin{array}{l}\text { Coronectomy } \\
\text { (intentional partial odontectomy of } \\
\text { lower third molars). }\end{array}$ & $\begin{array}{l}\text { Oral Surg Oral Med } \\
\text { Oral Pathol Oral Radiol } \\
\text { Endod }\end{array}$ & 2004 & Case series \\
\hline 14 & Renton et al. & $\begin{array}{l}\text { "A randomised controlled clinical trial } \\
\text { to compare the incidence of injury to } \\
\text { the inferior alveolar nerve as a result of } \\
\text { coronectomy and removal of } \\
\text { mandibular third molars" }\end{array}$ & Br J Oral Maxillofac Surg & 2005 & $\begin{array}{l}\text { Randomized } \\
\text { controlled trial }\end{array}$ \\
\hline 15 & Pogrel & "An update on coronectomy & $\begin{array}{l}\text { J Oral Maxillofac } \\
\text { Surg }\end{array}$ & 2009 & $\begin{array}{l}\text { Prospective } \\
\text { cohort }\end{array}$ \\
\hline 16 & $\begin{array}{l}\text { Dolanmaz et } \\
\text { al. }\end{array}$ & $\begin{array}{l}\text { A preferable technique for protecting } \\
\text { the inferior alveolar nerve: } \\
\text { coronectomy }\end{array}$ & $\begin{array}{l}\text { J Oral Maxillofac } \\
\text { Surg }\end{array}$ & 2009 & $\begin{array}{l}\text { Prospective } \\
\text { cohort }\end{array}$ \\
\hline 17 & Hatano et al & $\begin{array}{l}\text { Clinical evaluations of coronectomy } \\
\text { (intentional partial odontectomy) for } \\
\text { mandibular third molars using dental } \\
\text { computed tomography: a case-control } \\
\text { study" }\end{array}$ & $\begin{array}{l}\text { J Oral Maxillofac } \\
\text { Surg }\end{array}$ & 2009 & $\begin{array}{l}\text { Case control } \\
\text { study }\end{array}$ \\
\hline 18 & $\begin{array}{l}\text { Leung and } \\
\text { Cheung }\end{array}$ & $\begin{array}{l}\text { Safety of coronectomy versus excision } \\
\text { of wisdom teeth: a randomized } \\
\text { controlled trial" }\end{array}$ & $\begin{array}{l}\text { Oral Surg Oral } \\
\text { Med Oral Pathol } \\
\text { Oral Radiol Endod }\end{array}$ & 2009 & $\begin{array}{l}\text { Randomized } \\
\text { control }\end{array}$ \\
\hline 19 & Cilasun et al. & $\begin{array}{l}\text { Coronectomy in patients with high risk } \\
\text { of inferior alveolar nerve injury } \\
\text { diagnosed by computed tomography }\end{array}$ & $\begin{array}{l}\text { J Oral Maxillofac } \\
\text { Surg }\end{array}$ & 2011 & $\begin{array}{l}\text { Prospective } \\
\text { cohort }\end{array}$ \\
\hline 20 & $\begin{array}{l}\text { Leung and } \\
\text { Cheung }\end{array}$ & $\begin{array}{l}\text { Coronectomy of the lower third molar } \\
\text { is safe within the first } 3 \text { years }\end{array}$ & $\begin{array}{l}\text { J Oral Maxillofac } \\
\text { Surg }\end{array}$ & 2012 & $\begin{array}{l}\text { Prospective } \\
\text { cohort }\end{array}$ \\
\hline
\end{tabular}

\section{Table 1: Various authors and studies on coronectomy procedure}

\section{Conclusion}

Neurosensory deficit is a significant risk in lower wisdom tooth surgery. Due to the anatomical positions, the lingual nerve (LN) and inferior dental nerve (IDN) are at risk in the procedure, resulting in tongue numbness with taste disturbance in LN injury, or lower lip numbness in IDN injury on the affected side. The prevalence of LN and IDN deficits in the literature are $0.1-22 \%$ and $0.3-8.4 \%$, respectively. Dr. Mike Y Y LEUNG \& Prof. Lim K CHEUNG concluded in their study that increased age, unerupted wisdom tooth and the "old fashion" lingual split technique are significant risk factors and LN deficit. Rising of the lingual flap, which is supposed to protect the LN from rotary instruments, is also a risk factor to LN deficit at least on a temporary basis. In contrast, the risk of IDN deficit is increased with the depth of the impaction or exposure of IDN intraoperatively, which is easily explained by the proximity of IDN to the tooth roots and the increased difficulty of the surgery.

\section{References}

[1]. Knutsson K, Lysell L, Rohlin M. Postoperative status after partial removal of the mandibular third molar.Swed Dent J 1989; 13:15_ 22

[2]. Nerve damage and third molar removal a. R. Loescher, k. G. Smith and p. P. Robinson dent update 2003; 30: 375382

[3]. Chkoura Ahmed et. al. Coronectomy of Third Molar: A Reduced Risk Technique for Inferior Alveolar Nerve Damage. Dent Update 2011;38: 267-276

[4]. M. A. Pogrel, J. S. Lee, and D. F. Muff, "Coronectomy: a technique to protect the inferior alveolar nerve," Journal of Oral and Maxillofacial Surgery, 2004 vol. 62, no. 12, pp. 1447-1452

[5]. T. Renton, M. Hankins, C. Sproate, and M. McGurk, "A randomised controlled clinical trial to compare the incidence of injury to the inferior alveolar nerve as a result of coronectomy and removal ofmandibular thirdmolars," British Journal of Oral and Maxillofacial Surgery; 2005 vol. 43, no. 1, pp. 7-12 
[6]. B. C. O'Riordan, "Coronectomy (intentional partial odontectomy of lower third molars)," Oral Surgery, Oral Medicine, Oral Pathology, Oral Radiology and Endodontology; 2004 vol. 98, no. 3, pp. 274-280

[7]. L. Tolstunov, B. Javid, L. Keyes, and A. Nattestad, "Pericoronal ostectomy: an alternative surgical technique for management of mandibular third molars in close proximity to the inferior alveolar nerve," Journal of Oral and Maxillofacial Surgery; 2011, vol.69, no. 7, pp. 1858-1866

[8]. G. A. Bonetti, "In reply,” Journal of Oral and Maxillofacial Surgery; 2008 vol. 66, no. 6, p. 1317

[9]. Rood JP, Shehab BA. The radiological prediction of inferior alveolar nerve injury during third molar surgery. Br J Oral Maxillofac Surg 1990; 28: 20-25

[10]. Michael Leizerovitz and Olga Leizerovitz, Modified and Grafted Coronectomy: A New Technique and a Case Report with TwoYear Followup; Case Reports in Dentistry Volume 2013, Article ID 914173, 1-7

[11]. Freedman GL. Intentional partial dontectomy: review of cases. J Oral Maxillofac Surg 1997;55:524-6

[12]. M. A. Pogrel, J. S. Lee, and D. F. Muff, "Coronectomy: a technique to protect the inferior alveolar nerve," Journal of Oral and Maxillofacial Surgery, vol. 62, no. 12, pp. 1447-1452, 2004.

[13]. O'Riordan B. Coronectomy (intentional partial odontectomy of lower third molars). Oral Surg Oral MedOral Pathol Oral Radiol Endodontol 2004; 98:274-80

[14]. T. Renton, M. Hankins, C. Sproate, and M. McGurk, "A randomised controlled clinical trial to compare the incidence of injury to the inferior alveolar nerve as a result of coronectomy and removal ofmandibular thirdmolars," British Journal of Oral Maxillofacial Surgery, vol. 43, no. 1, pp. 7-12, 2005.

[15]. M. A. Pogrel, “An update on coronectomy," Journal of Oral and Maxillofacial Surgery, vol. 67, no. 8, pp. 1782-1783, 2009

[16]. D. Dolanmaz, G. Yildirim, K. Isik, K. Kucuk, and A. Ozturk, "A preferable technique for protecting the inferior alveolar nerve: coronectomy," Journal of Oral and Maxillofacial Surgery, vol. 67,no. 6, pp. 1234-1238, 2009.

[17]. Y.Hatano, K. Kurita, Y. Kuroiwa, H. Yuasa, and E. Ariji, "clinical evaluations of coronectomy (intentional partial odontectomy) for mandibular third molars using dental computed tomography: a case-control study," Journal of Oral and Maxillofacial Surgery, 2009,vol. 67, no. 9, pp. 1806-1814

[18]. Y. Y. Leung and L. K. Cheung, "Safety of coronectomy versus excision of wisdom teeth: a randomized controlled trial," Oral Surgery, Oral Medicine, Oral Pathology, Oral Radiology and Endodontology; 2009 vol. 108, no. 6, pp. 821-827

[19]. U. Cilasun, T. Yildirim, E. Guzeldemir, and Z. O. Pektas, Coronectomy in patients with high risk of inferior alveolar nerve injury diagnosed by computed tomography," Journal of Oral andMaxillofacial Surgery; 2011, vol. 69, no. 6, pp. 1557-1561

[20]. Y. Y. Leung and L. K. Cheung, "Coronectomy of the lower third molar is safe within the first 3 years," JJournal of Oral and Maxillofacial Surgery, vol. 70, no. 7, pp. 1515-1522, 2012

[21]. S. E. Lieblich,M.A.Kleiman, and J. ZakMJ, "Parameters of care:clinical practice. Guidelines for oral and maxillofacial surgery. (AAOMS ParCare 2012)," Journal of Oral and Maxillofacial Surgery, vol. 70, e50, 2012

[22]. T. B. Dodson, I. D. Cheifetz, W. J. Nelson, and L. K. Rafetto,"Summary of the proceeding of the third molar multidisciplinary conference," Journal of Oral andMaxillofacial Surgery, vol. 70, no. 9, supplement 1, pp. S66-S69, 2012

[23]. Nerve Damage and Third Molar Removal A. R. Loescher, K. G. Smith And P. P. Robinson Dent Update $2003 ; 30: 375$ 382.

[24]. Monaco G, de Santis G, Gatto MR, Corinaldesi G, Marchetti C. Coronectomy: a surgical option for impacted third molars in close proximity to the inferior alveolar nerve. J Am Dent Assoc. 2012 Apr;143(4):363-9.

[25]. T. A. Quee, D. Gosselin, E. P.Millar, and J.W. Stamm, "Surgical removal of the fully impacted mandibular third molar. The influence of flap design and alveolar bone height on the periodontal status of the second molar," Journal of Periodontology, vol. 56, no. 10 , pp. $625-630,1985$ 